\title{
DIE AANDEEL VAN DIE OU GEREFORMEERDES IN DIE VERWERPING VAN DIE INLYWING ONDER DIE KAAPSE SINODE.
}

By die benadering van hierdie belangrike, maar tot hiertoe veelal verwaarloosde onderwerp deur die meeste kerkhistorici in die verlede, wil ons stilstaan by I) die voorgeskiedenis; II) die inlywing assodanig, en III) die verwerping van die inlywing.

\section{I.-Die voorgeskiedenis.}

Die Kerkgeskiedenis is nie maar 'n dooie opeenstapeling van feite nie, maar dit is ook 'n belewenis van die gebeure. Elke gebeurtenis in die kerk van Christus op aarde en in besonder die belangrike historiese gebeure het nie maar uit die lug geval nie. Dit het 'n oorsaak of oorsake en daar is begryplikerwyse ook 'n gevoly of gevolge. Om die sg. inlywing van die Transvaalse Kerk onder die Kaapse Sinode op 13 Oktober 1852 te verstaan, is dit daarom noodsaaklik om die voorgeskiedenis goed in oënskou te neem.

Die Transvaalse Kerk het tot op hierdie datum nog geen vaste predikant gehad nie. Op die pogings van die Voortrekkers om 'n eie herder en leraar te bekom, word nie hier ingegaan nie enersyds, omdat dit nie betrekking het op ons bepaalde onderwerp nie en andersyds ondat dit as bekend aangeneem kan word. Genoeg is dit hier om net in die verbygaan te meld dat die Groottrek aanvanklik deur die Kaapse Kerk as uit die bose beskou en assodanig behandel is. ${ }^{1}$ ) Dat daar later 'n kentering gekom het, is bekend, maar die vraag bly nog steeds watter skade is aangerig wat nie maar in een dag of jaar uitgewis sou word nie.

Om nou 'n duidelike beeld van Transvaalse toestande wat sowel die kerklike as die staatkundige strominge aanhetref, te kry voor die koms van di. D. van der Hoff (1853) en D. Postma (1858) moet verw'ys word na die drie offisiële afvaardigings na Transvaal deur die Kaapse Kerkom die drie besoeke van Ds. A. Murray van Bloemfontein wat hy uit eie beweging onderneem het, daar te laat. ${ }^{2}$ )

(a) Die eerste afvaardiging, bestaande uit Ds. A. Murray snr., Ds. P. K. Albertyn en Oudl. B. Pienaar, hesoek Mooirivier in 1848.

Met hulle ankoms te Mooirivier op 10 April 1848, het hulle tot hulle teleurstelling bemerk dat daar groot onrus geheers het by die mense. In die verslag van die Kommissie aan die Sinode word daar, om ongenoemde redes, nie melding van die onrus gemaak nie. Ds. P. K. Albertyn vertel egter iets oor die agterdog van die mense teenoor die koms van die afvaardiging. Hy meld van 'n vrou wat aan hom vertel het dat sy van gedagte was dat die Engelse Regering van die Kaapkolonie die deputasie na Transvaal gestuur het. Sy het later, na toeligting, haar

1) Vgl. hiervoor die besluite deur die Kaapse Sinode van 1837 en die Ringsvergaderinge van $1838-1840$.

$\left.{ }^{2}\right)$ Vgl. hiervoor A. Dreyer: Die Kaapse Kerk en die Groot Trek, p. 96. 
agterdog egter laat vaar. Hierby het dit allig nie gebly nie, want daar was 'n nasleep oor die volgende woorde van Sir Harry Smith aan 'n sekere vriend Kruger van hom: ,These gentlemen (d.i. Murray en Albertyn) were sent by the Synod among you, for Christian and Political purposes". ${ }^{3}$ )

$\mathrm{Na}$ 'n hele woordwisseling tussen die aktuaris van die Sinode, die Kerkraad van Kaapstad en die Sinodale Kommissie, het die Advertiser die posisie soos volg opgehelder: die sin sou dan soos volg moes lees: "These gentlemen were sent by the Synod among you for Christian and not political purposes!"')

Hoe dit ookal sy, feit bly staan dat daar groot onrus was by die mense te Mooirivier oor die koms van die Kommissie namens die Kaapse Kerk. Hier moet dan ook meteens ofgemerk word dat baie dinge vandag deur kerkhistorici miskien makliker nagespeur sou gew'ees het as ons ou mense meer (en ook beter) sou geskrywe het. Maar ons moet ons probeer indink in hulle tydsomstandighede toe hulle weinig geleentheid gehad het om skoolonderrig te ontvang. Die ou mense het nie graag geskrywe nie.

Ter opheldering van wat hier te Mooirivier plaasgevind het, moet ook slegs verwys word na die ingenomendheid van ds. A. Murray van Bloemfontein met sommige mense. Hy sê sommige mense „w'ished to fear Gcd and honour the Queen ${ }^{5}$ ). Opmerklik dat Generaal A. W. J. Pretorius nie eers die dienste bygewoon het $n i^{6}{ }^{6}$ ).

(b) Die tweede afvaardiging het bestaan uit Ds. (later Dr.) P. E. Faure en Dr. W. Robertson en hulle het in dieselfde jaar (1848) Mooirivier en Magaliesberg besoek.

Net soos die geval was met die eerste deputasie, was dit ook met die besoek van die tweede: die mense by Mooirivier was onrustig, ook oor hierdie besoek. Die vraag kan m.i. tereg gestel word of dit daaraan toegeskryw'e moet word omdat Dr. Robinson die Groot Trek bestempel het as 'n "foolish idea" en die moorde in Natal as 'n afkeuring van God oor die Trek en dat Ds. Faure deur die Sinodale Kommissie afgevaardig is ,accordance with the wishes of His Excellency?"?) Die leraars het egter aan die landdros van Mooirivier verduidelik dat die sending kerklik en geestelik van aard is waarop die gemoedere andermaal bedaar het.

Van Mooirivier het die deputasie na Magaliesberg vertrek waar daar, nieteenstaande kort kennisgewing, sowat 'n duisend mense bymekaar gekom het. Die aste is gehou en ampsdraers is bevestig (die gemeente is eers in 1850 gestig). Die nasleep het egter gekom oor die reiskoste wat blykbaar deur die Kaapse Goewerment hetaal is, want die Kaapse

3) S.A. Commercial Advertiser, 2 Sept. 1848.

6) Vgl. A. Dreyer : a.w., p. 60.

5) Prof. Dr. S. P. Engelbrecht: Kerkgeskiedenis, p. 60.

6) Prof. Dr. S. P. Engelbrecht: a.v., p. 59.

7) A. DREYER: a.41., pp. 8 en 133. 
Kerk het dit nie betaal nie. Die twee predikante het Sir Harry Smith egter versoek om die koste te betaal want ons lees: "With regard to the payment of their expenses these gentlemen requested that they might in the first instance defray their expenses themselves, apprehending it might injure the cause if the expences were advanced by the Government. They will upon their return, state what has been the cost to them of the Mission with a view to its being reimbursed to them from the Public Treasury $\left.{ }^{8}\right) "$

Toe die Ring van Kaapstad aan die Sinodale Kommissie gevra het wie die onkoste betaal het, het hulle geweier om daarop te antwroord en meegedeel dat hulle nie aan die Ring verantwoording verskuldig is nie. ${ }^{9}$ )

(c) Die derde afvaardiging wat bestaan het uit Di. A. Murray jnr., J. H.

Neethling het in 1852 Mooirivier, Magaliesberg en Lydenburg besoek.

Die afvaardiging het voortreflike werk gedoen en selfs Soutpansberg - die vierde in Transvaal - tot ' $n$ afsonderlike gemeente gestig.

Op 21 Mei 1852 is kerkraadsvergadering gehou te Mooirivier. Die kwessie van 'n beroep van 'n Kaapse Predikant het andermaal ter sprake gekom. Ds. Neethling was gewillig om hierin behulpsaam te wees „,maar verklaart dat dit hem onmogelijk sal zyn voor en aleer hij een bevredigend antwoord op de volgende vragen zal hebben ontvangen. Hij vraagt:

i. Zal de leeraar, zullen de leeraren der Maatschappy, leden blyven van de Synode der Gereformeerde Kerk van Zuid-Afrika, en blyven de gemeenten alhier hoewel burgerlijk afgezonderd, geestelijk onder de zorg en gezag van de Synode?

ii. Zal aan den leeraar een jaargeld naar bepaling vroeger gemaakt: Rd. 3000 - drieduisend-worden toegekend en door den Raad op gezette tijden aan hem uitbetaald gelijk dit in de Colonie door't Goevernement geschiedt ${ }^{10}$ ).

Ds. Neethling gee verder die versekering dat die staatkundige vryheid hoegenaamd nie aangetas sou word deur 'n inlywing onder die Kaapse Kerk, maar dat dit tewens 'n vrywaring sal wees teen ,,menig valschen leeraar," asof die Britse vlag 'n waarborg is teen geestelike verval!"11)

Aan hierdie ultimatum van Ds. Neethling, nou het sowel die Kerkraad van Mooirivier as die Volksraad van die S.A. Republiek toegegee, nl. dat 'n predikant van die Kaapse Kerk beroep mag word en hiermee het ons vanself tot die tweede hoofpunt onder bepreking gekom.

II.-Die inlywing assodanig.

Inlywingskwessies is altyd moeilike kwessies, so-ook hierdie een. Oor hierdie kwessie heers daar groot verwarring en daarom is dit dringend noodsaaklik om hierop in te gaan. Die vraag: Was die Transvaalse Kerk

8) A. Dreyer: a.w., p. 134.

๑) Vgl. A. Moorrees: Kerkgeskiedenis, p. 736.

10) Prof. Dr. S. P. Engelbrecht: Kerkgeskiedenis, p. 75, noot 1.

11) Vgl. Prof. Dr. S. P. Engelbrecht: a.w., p. 75, noot 1. 
ingelyf by die Kaapse Sinode of nie, moet nou pertinent beantwoord word.

Selfs hierdie aangeleentheid het 'n voorgeskiedenis waarop eers kortliks geattendeer moet word en dit is nl. die versoek van Ds. Andrew Murray jnr., (Bloemfontein) en sy broer Ds. John met hul besoek op 21 April 1851 aan die kerkrade van Potchefstroom en Rustenburg om verteenwoordigers te stuur na die Ring van Transgariep. Die bedoeling van hierdie, op sigself vriendelike uitnodiging van die twee predikante, was dan dat albei die gemeentes hiermee as vanself ingelyf sou wees onder die Kaapse Sinode. Die kerkrade wou egter hiermee nie akkoord gaan nie, nie omdat hulle assodanig bevrees was vir die Kaapse Kerk nie, maar wel vir die Britse invloed in die Kaapse Kerk.

Maar ons moet terugkom tot die redenasie van Ds. Neethling. Op die kerkraadsvergadering van 12 Mei 1852 te Potchefstroom soos hierbo aangehaal. Hoe hy dit gerym kon kry dat die staatkundige vryheid van die Transvaal nie in gedrang sou kom deur 'n kerklike inlywing onder die Kaapse Kerk nie, val moeilik te begryp, terwyl die Kaapse predikante tog deur die Engelse Goewerneur angestel moes word. Wat die tweede punt van sy argument aanbetref nl. dat ' $n$ inlywing onder die Kaapse Sinode die Transvaalse Kerk van geestelike afval sou kon bewaar, hoef nie op ingegaan te word nie! Die Trekkers was nou alreeds 16 jaar herderloos en het nog steeds gesoek na 'n predikant-'n bewys dat hulle in elk geval nog nie so erg in geestelike verval was nie!

Hoe dit ookal sy, die kerkraad van Potchefstroom het toegegee aan die ultimatum, nl. dat' $n$ predikant van die Kaapse Kerk beroep mag word, maar het dit as 'n afpersing beskou want hulle was nou al 16 jaar herderloos en mens kan verstaan dat sommige mense al begin moedeloos word het. Ook die Volksraad het die saak in rype oorweging geneem en dit goedgekeur dat 'n predikant van die Kaapse Kerk beroep mag word en Di. Neethling en Murray versoek om nou tog 'n predikant vir hulle te vind. Maar dit moet hier baie duidelik gekonstateer word dat nòg in die Volksraadsnotule, nòg in die antwoord aan di. Neethling en Murray een enkele woord vermeld word van die inlywing self. ${ }^{12}$ ). Dit dien ook hier vermeld te word dat nòg Ds. Neethling nòg Ds. Murray met enige woord daarvan melding gemaak het dat die Kaapse predikante deur die Engelse goewerneur aangestel word, hoewel ons kan aanvaar dat die kerkraadslede dit behoort te geweet het. Verder, die twee predikante moes die Kaapse kerkwet hier totaal buite rekening gehou het want volgens Ordannansie 7 van 1843 het die Kaapse Kerk geen jurisdiksie oor die gemeentes buite die grense van die kolonie gehad nie soos dan ook later ten duidelikste bewys is met die hofsaak van 1862. Tereg sê Dr. S. P. Engelbrecht in hierdie verband: „Halfhartig en onder pressie is aan die eis en ultimatum van Ds. Neethling toegegee, want dit was noual sestien jaar dat die Voortrekkers in Transvaal gekom het, en nog altyd was hulle sonder predikant, maar hulle het die saak as ,afgeperst' beskou.

12) Vgl. Piof. S. P. Engelbrecht: a.w., p. 76. 
Ds. Neethling het hulle mislei deur ' $n$ onjuiste voorstelling van sake te gee, en die kerkwet skeef voor te stel"13). Hoe moedeloos sommige mense en selfs leiers soos A. W. J. Pretorius en hoof-kommandant C. J. Kruger reeds al w'as as gevolg van die herderlose toestand getuig 'n dankbetuiging wat hulle reeds al in 1848 uitgespreek het en waarin selfs die wens vervat is om dan maar liewer onder die Kaapse Kerk te ressorteer: ,,indien wij dan mede als een gemeente onder de Zuid Afrikaansche Hollandsch Gereformeerde Synode opgenomen en Bestuurd mogen worden, dan! ja dan! zouden wij nog verder hoop krijgen dat de zon des vredes en des geluks ons weder op nieuw beschijnen zoude"14). Maar-..en dit is 'n groot maar-dinge het vir baie wat hierdie sienswyse begin toegedaan raak het, hoe langer hoe meer duidelik geword dat dit fataal sou wees om kerklik onder die Kaapse Sinode te ressorteer met die gevolg dat hulle van sienswyse verander het soos die geskiedenis dan ook later duidelik uitgewys het. Dat daat wel mense was wat graag onder die Kaapse Sinode wou ressorteer het die geskiedenis ook bewys. As voorbeeld noem ons slegs die naam van Charl Cilliers wat 'n vurige voorstander was van inlyw'ing en verder word gewys na die geskiedenis van die Lydenburgse gemeente.

Die Kaapse Sinode vergader op 12 Oktober 1852 d.w.s. sowat 5 maande na die bovermelde besoek van di. Neethling en Murray aan die Potchefstroomse kerkraad. Op hierdie Sinode dien daar nou 'n beskrywingspunt wat deur die twee predikante ingedien word en wat gelui het "Inlyving der Transvaalsche Gemeente". In gedagte moet gehou word dat nòg die Kerkraad van Potchefstroom nòg die Volksraad van Transvaal enige besluit geneem het insake inlywing onder die Kaapse Sinode. Maar selfs dit daargelaat. Op die Sinode het Dr. S. P. Heyns gewaarsku dat die Sinode geen jurisdiksie besit buite die grense van die Kolonie nie. Ordonnansie 7 van 1843 handel slegs oor die Kerk ,binnen deze Kolonie".

Op 15 Oktober word deur die Sinode besluit om die opinie van die Prokureur-Generaal Sir William Porter in te win. Die Sinode het deur middel van 'n paar van sy lede die saak mondeling aan Porter gaan voorlê. Op 16 Oktober (daar kan nie presies uitgemaak word of die deputasie op 15 of wel op 16 Oktober by Porter was nie ${ }^{15}$ ) gee die ProkureurGeneraal skriftelik advies wat daarop neerkom dat die inlywing van die Transvaalse Kerk nie in stryd sou wees met die Ordonnansie nie. Toe die advies voor die Sinode dien, het Ds. Neethling in sy relaas dit so voorgestel dat die Transvaalse Kerk aansoek gedoen het om inlywing!, waarop deur die Sinode 'n kommissie benoem word om die voorwaardes van inlywing op te stel wat daarop neerkom dat die Transvaalse Gemeentes geheel-en-al volgens die Kaapse Kerkw'et bestuur sou word en onder die Transgariepse Ring sou ressorteer. Die Sinode het hierop die inlywing

13) Prof. Dr. S. P. Engelbrecht, a.w., p. 76.

14) A. Dreyer: a.u., p. 146.

15) Vgl. Prof. Dr. S. P. Engelbrecht : a.ll., p. 76, noot 2. 
goedgekeur maar nie voordat Ds. G. W. A. van der Lingen, een van die kommissie lede daarvan melding gemaak het dat ofskoon hy die rapport onderteken het hy nie met alles arat daarin voorkom, kon saamstem nie ,en dat hy voorsag dat de bepalingen door de Synode aangenomend zijnde, in de gevolgen groote botsingen en moeijlijkheden zouden worden ondervonden"16).

Die Sinode het dus die inlywing goedgekeur sonder skriftelike versoek van die Transvaalse Gemeentes en die aktuaris, Dr. A. Faure, het sodanig kennis gegee aan die Engelse Goeverneur in Kaapstad en ook aan die Transvaalse Gemeentes met opgawe van die gestelde voorwaardes. 'n Antwoord het egter uitgebly vanuit Transvaal waarop Dr. Faure die hele situasie maar as twyfelagtig beskou , of de Transvaalschen de voorwaarden gaaf zullen aannemen". Hy het egter later, en wel op 11 April 1853, 'n tweede brief aan Potchefstroom gestuur. Op 6 Junie het die kerkraad egter besluit ,geen officieël antwoord te geven voordat alle Kerkeraden hieromtrent gehoord zijn". Die Transvalers het egter intussen gehoor dat daar 'n predikant uit Holland op die pad was. Op die vraag nou, hierbo gestel, of die Transwaalse Kerk acel ingelyf was by die Kaapse Kerk, moet dus ontkennend geantuoord uord. Maar soos ons wel kan begryp was die lug vol van die inlywingskwessie. 'n Algemene Kerkvergadering is egter belê vir 8 Augustus 1853 en hiermee het ons nou ook as vanself aangekom by die aandeel van die ou Gereformeerdes om moontlike inlywing totaal te verwerp.

\section{III.--Die Veruerping van die inlyuing.}

Soos wel te begrype is, w'as die jaar 1853 van groot betekenis vir die Transvaalse Kerk omdat in daardie jaar Ds. D. van der Hoff as eerste vaste predikant daar aangekom het, asook om die feit dat in daardie jaar hesluit is om die inlywing by die Kaapse Sinode finaal te verwerp.

Die eerste Algemene Kerkvergadering waarna hierbo alreeds verwys is, het op 8 Augustus 1853 te Rustenburg vergader waar daar toe reeds 'n hele aantal mense teenwoordig was omdat hierdie kerkaangeleentheid groot belangstelling gaande gemaak het. Ouderling Wolmarans was voorsitter en Ds. Van der Hoff scriba. Die eerste op die Sinodetafel was dan ook die sg. inlyw'ingskwessie.

Die persoon wat die inisiatief geneem het om die inlywing nou finaal te verwerp was Ouderling $\mathrm{Ph}$. Snyman van Rustenburg, een van die voorvegters van die Gereformeerde Kerk in Transvaal. Wat hier van die uiterste belang is, is 'n brief wat hy op 14 Februarie 1853 aan Generaal A. W. J. Pretorius geskryf het, d.w.s. toe Ds. van der Hoff nog in Kaapstad vertoef het. Hierdie brief lui soos volg:

„Moddervontyn den Veertien den Veebruwaarie 1853. Mijn heer A. pretoory Comdant Genraal.

16) Gedrukte Notule van die Sinode, pp. 20 en 28. 
Mijn heer ik doet $\mathrm{u}$ weeten dat ik niet hier kan weesen aan mooijrivier soo is mijn versoek dat $u$ als $u$ blief om den saak in mijn plaats te verreg soos ik daar self is mijn heer mijn versoek is dat $u$ het sal verreg of $\mathrm{ik}$ er self is mijn heer sorg tog dat ons tog niet naader verpant wort aan den Kaap seijn nooden geliefde heer neem het tog voor mijn maar als $u$ blief in als het noodig is teeken meijn naam als het nodig is per order als ouderling ik blijfe u goede vrint in dienaar $\mathrm{Ph}$. Snyman

\section{Ouderling"17).}

Generaal Pretorius het na ontvangs van hierdie brief 'n krygsraadsvergadering belê vir 31 Mei 1853 waarop die bevestiging van Ds. Van der Hoff asook die moontlike inlywing onder die Kaapse Sinode bespreek is. Volgens die notule van die krygsraadsvergadering is ,,op dringende versoek van den ouderling Snyman van Rustenburg" besluit om 'n Algemene Kerkvergadering te Rustenburg te hou tesame met die Krygsraad en die Volksraad om bg. twee sake te bespreek. Op hierdie Krysraadsvergadering was o.a. ook teenwoordig die heer Stephanus Kruger-ook een van die voorvegters van die Gereformeerde Kerk in Transvaal, asook H.A. Pretorius (ook genoem Bart), broer van Kommandant-Generaal A. W. J. Pretorius.

Kort na bg. Krygsraadsvergadering het Kommandant-Generaal A. W. J. Pretorius 'n besoek afgelê by Ds. Van der Hoff te Potchefstroom Met hierdie gedenkwaardige besoek-A. W. J. Pretorius is kort hierna nl. op 26 Julie 1853 oorlede-het Pretorius Ds. D. van der Hoff dringend versoek om hom nie te laat bevestig ,,door een predikant van de Synode" voordat die voorgenome byeenkoms te Rustenburg plaasgevind het $n_{i e}{ }^{17}$ ). $\mathrm{Ph}$. Snyman moes aan Ds. Van der Hoff 'n dergelyke brief as aan Kommandant-Generaal Pretorius geskrywe het, want Ds. Van der Hoff maak in bovermelde „Stem" as volg hiervan melding: „Een dergelijke versoek had ik ook ontvangen van een ouderling der gemeenten Rustenburg. Dientengevolge schreef $\mathrm{ik}$ aan den predikant van Bloemfontein, om mijne voorstelling aan de gemeente uittestellen, en begon ernstig over de zaak na te denken ${ }^{19}$ ).

Op die reeds genoemde Kerkvergadering, nou, van 8 Augustus 1853 te Rustenburg, is na langdurige beraadslaginge (hieroor straks) besluit om ,de inlyving onder die Kaapse Synode niet goed te keuren en wel om de volgende reden:

1e Omdat aan de voorwaarde of belofte om ons door bemiddeling der Kerk Synode van leeraars te zullen voorzien, niet voldaan is.

Ze Omdat men zich aan de kerkelijke wetten der Nederd. Geref.Kerk in Zuid-Afrika, onder de Sijnode, niet kan onderwerpen ${ }^{20}$ ).

17) T.S.A.: SS 5 R $541 / 53$.

18) "Eene stem uit de Kaapstad door den Advokaat Brand weerklonken in Mooiriviermet eenige aanmerkingen en toevoegselen uitgegeven door D. VAN DER HOFF (1857)", p. 2.

19) Eene Stem uit de Kaapstad ens., p. 2.

20) T.K.A., N.H.K. I, pp. 3 en 4. 
Van hierdie besluit is kennis gegee an die Volksraad wat op sy heurt dit bekragtig het ${ }^{21}$ ).

Met ander woorde: hiermee is aan die hele angeleentheid beslag gegee en wel op inisiatief van $\mathrm{Ph}$. Snyman-een van die latere voorvegters van die Gereformeerde Kerk.

Hierbo is gespreek van die langdurige beraadslaginge op die kerkvergadering. Wat was die posisie?

Ds. Van der Hoff was anvanklik vir inlywing onder die Kaapse Sinode en sy beweegredes kan bes weergegee word deur volledig uit die hetrokke notule an te haal. Ons lees hieromtrent: „Het punt der inlijving onzer gemeenten onder de Kaapsche Sijnode ter tafel komende, vraagt de leeraar het woord. $Z$ ijn Eerw. geeft den wensch te kenne dat de gemeenten alhier onder de K. Sijnode mogten ingelijfd worden. Hy stelt der vergadering het voordeelige en wenschelijke dier zaak voor en waarschuwt ernstig voor de nadelige gevolgen die uit eene weigering der inlyving kunnen voortvloeijen. De geheele vergadering is echter van een geheel ander gevo len. Haar hoofdleus is: burgerlijk vrij en onafhankelijk, wenschen wij dit ook in het kerkelijke. Wij wenschen onze eigene kerkelijke zaken zelf te besturen, en in deze niet ondergeschikt te zijn aan de Kaapsche Synode. De Koning der Kerk Jezus Christus onze Heer, zij ons eenige hoofd. Deze en dergelijke andere uitdrukkingen door krachtige drangredenen, te veel om hier te vermelden, ondersteund, deed $\mathrm{d} n$ leeraar eindelijk ook besluiten zijne toestemming te geven aan den algemeenen wensch des Kerkeraads, die volgens het zeggen der kerkraadsleden, ook de algemeen wensch van het publiek was." ${ }^{22}$ ).

Wat die twee redes vir die verwerping aanbetref dien net daarop gewys te word dat wat punt 1 aanbetref dit eintlik 'n onbillike rede was want die Kaapse Sinode het weinig tyd gehad na sy besluit tot inlywing (16 Oktober 1852) om Transvaal met predikante te voorsien en buitendien daar wat tot op datum ook nog geen antwoord op hulle skrywe nie! Dat dit wel vòòr die tyd die geval was waar die Kaapse Kerk gouer en beter kon gehelp het, is nie te betwyfel nie. Die eintlike rede word onder punt 2 aangegee. Prof. Dr. S. P. Engelbrecht teken hierby aan: „Die beswaar was nie teen die Kaapse Kerk as Kerk nie, maar teen die bande waarmee die kerkorganisasie aan die Britse Goewerment gebonde was." Die Kaapse predikante moes naamlik deur die Engelse Goewerneur aangestel word en dit spreek vanself dat dit 'n gevaar ingehou het vir die sterk nasionale gevoel van Transvaal. Maar daar kom nog iets by en dit is die gelykstellingsbeleid wat in die Kaapse Kerk tot op 1857 gangbaar was. Terwyl die Voortrekkers enduit segregasie op sowel die staatkundige as die kerklike akker bely en toegepas het. Die Kaapse Sinode het selfs in 1857 verklaar dat gelykstelling ,,wenschelijk en schriftmatig" is maar as gevolg van die swakheid van sommige is dit aanbeveel

21) T.K.A., N.H.K. I. pp. 3 en 4.

$\left.{ }^{22}\right)$ Prof. Dr. S. P. Engelbrecht, a.w., p. 93. 
dat afsonderlike geboue vir blank en nie-blank opgerig moet word. ${ }^{23}$ ). In hierdie verband skrywe Dr. A Moorrees dat die eintlike motiewe vir die besluit verswyg is. „Dit was naamlik vrees vir bemoeiing van die Britse regering met die inwendige aangeleenthede van die Republiek; vrees vir wat hulle noem gelykstelling en die grote koste."24) Deur sommige geskiedskrywers word beweer dat dit aan die koms van Ds. van der Hoff toegeskryf moet word dat die inlywing verwerp is, ,,maar dit wil nie sê dat hy dit bewerk het nie" ${ }^{25}$ ). Maar ons meen dat dit hierbo voldoende uit die geskiedenis bewys is dat die akker voorberei was voor die koms van Ds. van der Hoff-vgl. die inisiatief van $\mathrm{Ph}$. Snyman en A. W. J. Pretorius. Maar Ds. Van der Hoff maak self daarvan melding wie die oorsaak is as hy sê: „De oorzaak van dien afval is de gemeente. Tot getuigen roep ik op al de oude emigranten die destyds de drijvers van de zaak waren. Ik zal hier enkele bij namen noemen als $\mathrm{Ph}$. Snyman, $\mathrm{Ph}$. Schutte, Gerrit, Paul en Douw Kruger, G. Engelbrecht, Th. Steyn, J. Kok, Wynand Smit, D. Jacobs, de familien Wolmarans, Lombard en anderen. Ge kunt ook aan onze Staatspresident vragen wat zijn overleden vader hem kort voor zijn dood op het hart heeft gedrukt, namelijk: Om wel te zien dat ik mij niet onder de Kaapsche Synode moest verbinden."

Later toen ik inzag dat de scheiding van de Synode eene gewenschte zaak was, heb ik ijverig daarvoor gewerkt. En wat betreft het doel der scheiding, dat was niets anders dan een uitmuntende zorg om de vrijheid en de onafhankelijkheid der emigranten te bewaren, maar niet zooals gij herhaaldelijk beweert, het invoeren van den liberalisme. Aan zulk een gruwel werd destijds volstrekt niet gedacht." $\left.{ }^{26}\right)$. In Eene Stem uit Mooirivier ${ }^{27}$ ) verskyn daar ook 'n stuk oor die onderhawige aangeleentheid, onderteken o.a. deur Ph. Snyman, waarin daar o.a. gewys word op die Britse aspek van die Kaapse Kerk.

En hiermee kan nou volstaan word nl. wat Ds. Van der Hoff se aksie in hierdie saak was.

Wat die andeel van die ou Gereformeerdes was om die inlywing te verwerp is ook al duidelik. Behalwe Ph. Snyman wat die inisiatief geneem het, noem Ds. Van der Hoff nog die name van Ph. Schutte, Gerrit, Paul (S. J. P. - die latere President) en Douw Kruger, almal leiers van die latere Gereformeerde Kerk. Dit is moontlik dat daar nog meer Gereformeerdes was wat die stryd help stry het, maar sover ons kan nagaan word nie meer name genoem nie. Dat daar Hervormers by was spreek vanself en die name hierbo genoem is dan ook 'n sprekende bewys

23) Handelinge van die Sinode, 1857, p. 60.

24) A. Moorrees, Kerkgeskiedenis, p. 780 . Sien ook my: Die Ontstaan van die Gerefor. meerde Kerk, p. 141.

25) A. MOORREES, a.w., p. 775.

26) Ds. D. VAN DER Hoff, Open Brief aan Ds. J.P. Jooste in antwoord op de zijne van Mei 1871 , pp. 1 en 2 .

27) Elpis, 1858, p. 49. 
van die aksie wat hulle gelewer het. Engelbrecht is die latere kommandant van Standerton, Steyn 'n lid van die Volksraad, Smit kom van suikerbosrand, Jacobs is die katkisasiemeester en ouderling van Suikerbostand, die Wolmaranse is van Potchefstroom en Lombard is die landdros van Potchefstroom. Dat daar ook mense in hierdie kontrei was van die (latere) Nederduits Gereformeerde Kerk wat hulle vir hierdie saak beywer het, kan seker ook nie ontken word nie.

Hierdie studie kan nou afgesluit word deur daarvan melding te maak dat lank nadat die besluit op die Algemene Kerkvergadering van 8 Augustus 1853 geval het, om die inlywing onder die Kaapse Sinode te verwerp, daar nog Gereformeerdes en Hervormers was wat opgetree het teen die verengelsingspolitiek wat op Transvaal wou inwerk via die Kaapse Kerk.

Gedurende die jaar 1856 het die Sinodale Kommissie van die Kaapse Kerk di. J. H. Neethling en A. A. Louw na Transvaal gestuur. Tot groot ontsteltenis van President M. W. Pretorius is sommige mense opgesweep teen die Transvaalse Kerk. Dit was juis op die tydstip toe President J. N. Boshoff van die O.V.S. 'n vriendelike brief aan Pretorius geskryf het oor samewerking tussen die twree Republieke. Pretorius antwoord soos volg: „dit is ook mijn inziens doch door bemoeijingen van predikanten en ander perzonen in de O.V. met onze saken ontstaan er ongenoegen en verwarringen, dat ligt zoo het niet gestaakt wordt, erger worden kan en broedertwist en broedermoord zal et het gevolg van wezen"28).

Die gevolg van hierdie opsweping in Transvaal was dat President Pretorius en fungerende kommandant-generaal T. F. Dreyer--'n Hervormer en 'n Gereformeerde-op verskeie plekke in 1856 byeenkomste in Transvaal toegespreek het om die gevoelens van die mense te pols. Op hierdie vergaderings is orals besluite geneem dat die mense nie onder die Kaapse Sinode ingelyf wil wees nie maar dat hulle slegs broederlike betrekkinge wil onderhou. Op staatkundige gebied wil hulle onafhanklik bly voortbestaan. Op Krokodilivier byvoorbeeld is besluit dat „,de ingezetenen van hier niet voornemens ben hun onder de Synode wetten te verbinden maar in een broederband blijfe als geloofsgenooten van een en de zelfde leer"'29). En op 8 Oktober 1856 op die plaas van J. J. Prinsloo: „De publiek zijn volstrekt er tegen om hun kerk en leeraar te verbinden onder de $\mathrm{Zynode.} \mathrm{Zij}$ is van gevoelen hun kerk zoo wel als hun staat onafhankelijk te houden onder hun eigene kerkelijke reglementen als burgerlijke wetten" ${ }^{30}$ ). Op Klerksdorp is besluit dat hulle kerklik en staatkundig onafhanklik wil bly en met die Kaapse Kerk broederlike verstandhouding wil onderhou ,zoo verre Gods Woord het toelaat". Op meer ander vergaderings is onder leiding van Pretorius en Dreyer

28) T.S.A.: SS 11 R. 982/56.

20) T.S.A.: SS 12 R 1212/56.

s0) T.S.A.: SS 12 R 1213/56. 
dieselfde beleid aanvaar nl. staatkundig en kerklik onafhanklik te wil bly voortbestaan ${ }^{31}$ ).

Hiermee word egter nie beweer dat hierdie gevoelens honderd persent verteenwoordigend van Transvaal was nie want uiteindelik het die posisie hom soos volg gekonsolideer: die Pretorius en Potgieter ondersteuners wat hoofsaaklik te Rustenburg, Potchefstroom en Soutpansberg gewoon het, was beslis ten gunste van 'n eie onafhanklike kerk en staat in Transvaal terwyl die mense van Lydenburg en Utrecht hoofsaaklik sowel kerklik as staatkundig onder die Kaapse Kerk en onder Britse bestuur wou ressorteer.

Van die reeds genome besluit van 8 Augustus 1853 te Rustenburg is egter nooit afgesien nie en dit het daartoe meegewerk dat die kerklike lewe van die Hervormde Kerk in Transvaal beslag gekry het en wat die Gereformeerdes aanbetref, hulle was van die begin af hoofsaaklik Republikeine.
B. R. Krüger. 